\title{
Electrochemical analysis of water and suds by impedance spectroscopy and cyclic voltammetry
}

\author{
R. Gruden ${ }^{1}$, A. Buchholz ${ }^{1}$, and O. Kanoun ${ }^{2}$ \\ ${ }^{1}$ Seuffer GmbH \& Co. KG, Bärental 26, 75365 Calw-Hirsau, Germany \\ ${ }^{2}$ Technische Universität Chemnitz, Reichenhainer Strasse 70, 09126 Chemnitz, Germany \\ Correspondence to: R. Gruden (roman.gruden@ seuffer.de)
}

Received: 31 August 2013 - Revised: 10 June 2014 - Accepted: 21 June 2014 - Published: 3 July 2014

\begin{abstract}
Optimum detergent dosage during a washing process depends on water quality, degree of pollution and quantity of laundry. Particularly, water quality is an important factor. Other parameters like carbonate- or non-carbonate hardness and calcium/magnesium $(\mathrm{Ca} / \mathrm{Mg})$ ratio in addition to total hardness of water have an impact on the amount of detergent. This work discusses the possibilities realizing a detergent sensor that measures important parameters for the washing process and assess the ideal necessary amount of detergent during the washing process. The approach is to combine impedance spectroscopy with cyclic voltammetry in order to determine both water quality and concentration of detergent in the suds which build up the basis for an optimum detergent dosage. The results of cyclic voltammetry show that it is possible to identify the $\mathrm{Ca} / \mathrm{Mg}$ ratio and the carbonate hardness separately, which is necessary for the optimization of the washing process. Impedance measurements identify total hardness and detergent concentrations.
\end{abstract}

\section{Introduction and motivation}

This work is an extension of the conference article (Gruden and Kanoun, 2013a) ${ }^{1}$.

In 2010 more than 580000 tons of detergent and more than 1 billion liters of water were used in Germany for washing the laundry. On average, $30 \%$ of the detergent is superfluous, resulting in water wasting during the rinsing process with an impact on environmental burden (Rüdenauer and Gensch, 2008).

Due to the higher concentration of detergent in the suds, more and longer rinsing processes are required to get rid of the detergent residues in the laundry. This requires not only higher water consumption but also more energy. If the rinsing process is adapted to the higher detergent concentration, the remaining residues can cause allergic reactions in sensitive individuals.

Furthermore, the washing result, customized to the individual properties of this load, is only optimal at one detergent

\footnotetext{
${ }^{1}$ Gruden, R. and Kanoun, O.: Water quality assessment by combining impedance spectroscopy measurement with cyclic voltammetry, AMA Sensor, Nürnberg, 2013.
}

quantity (Wagner, 2010; Smulders et al., 2002; Jakobi and Löhr, 1987).

At the present time automatic washing machines use only a control strategy that does not take the water quality or the actual properties of the laundry into consideration (Wagner, 2010; Smulders et al., 2002; Jakobi and Löhr, 1987). Moving to a regulation strategy by maintaining the washing result needs key parameters such as water quality, quantity of laundry (weight), concentration of dirt and concentration of detergent to be able to compute an optimal dosage.

The water parameter currently used for detergent dosage is total hardness. But it is also important to measure the carbonate hardness and the $\mathrm{Ca} / \mathrm{Mg}$ ratio because these parameters also influence the washing performance, too. The hydrogen carbonate ion $\mathrm{HCO}_{3}^{-}$, which is reasonable for the carbonate hardness, reacts to calcium carbonate which attaches to the heating elements in the washing machine and causes damages; calcium and magnesium form insoluble soaps which decrease the washing performance. The $\mathrm{Ca} / \mathrm{Mg}$ ratio influences the washing performance because calcium soaps are more insoluble than magnesium soaps. 
These parameters should be measured online during the washing process with a robust low cost sensor (Gruden et al., 2012), in order to save resources, protect the environment and avoid allergic reactions (Tröltzsch, 2012).

\section{State of the art and new approaches}

Optical methods such as turbidity sensors are presently used for automatic detergent dosage (Tschulena and Lahrmann, 2006; Czyzewski et al., 1999), but they are sensitive to contamination and especially to the dirtiness water; furthermore, water parameters cannot be detected with turbidity sensors.

Base-acid titration is able to determine precisely the value of total hardness and the $\mathrm{Ca} / \mathrm{Mg}$ ratio (Hütter, 1990) but this method is very expensive and works only under laboratory conditions.

Commercial online methods used for environmental investigation (Huang et al., 2005; Kräuter et al., 2006) and distribution systems (Verberk et al., 2006) focus on other water components and are too expensive for household lowcost applications. Voltammetric methods combined with ionselective electrodes are expensive (Cammann and Galster, 1996) and not suitable for detergent determination because of complex and different detergent composition (Wagner, 2010). Low-cost applications need environmental harmful mercury electrodes to determine the water parameters (Pungor et al., 1977). Both methods are not feasible inside the washing machine during the washing process.

Electronic tongues are sensor arrays combined with voltammetric methods and multi-variable analysis (Winquist et al., 1997; Winquist, 2008) which are tested for large household appliances:applications (Winquist, 2011; Ivarsson, 2003; Eriksson et al., 2011). The existent problem is the complex data analysis. To have information about total hardness, conductive methods are more suitable, but they are generally not sufficiently accurate because the conductivity of the electrolyte $\chi_{\mathrm{E}}$ depends on the total ion concentration including even ions which are not interesting for the washing process. Moreover $\chi_{\mathrm{E}}$ is frequency dependent and the results of the established methods which use only one frequency is incorrect.

Suds investigations with surface acoustic wave (SAW) sensors have been tested successfully to detect single sufactant concentrations (Vivancos et al., 2012). The investigation of water parameters, surfactant mixtures and critical micelle concentration (CMC) are not shown. Moreover, frequencies of $f>60 \mathrm{MHz}$ are needed for the SAW application and such electronic circuits are too expensive for the application in white goods.

Electrochemical impedance spectroscopy (EIS) and cyclic voltammetry $(\mathrm{CV})$ are well-known analytical methods (Barsoukov and Macdonald, 2005; Brad and Faulkner, 2001) and deliver more specific information. For analysis of suds during the washing process they have not yet been applied.

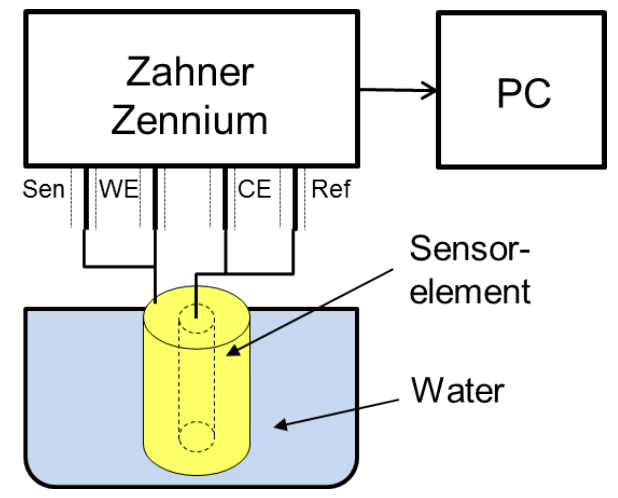

Figure 1. Measurement setup of Zahner Zennium for EIS and CV measurements.

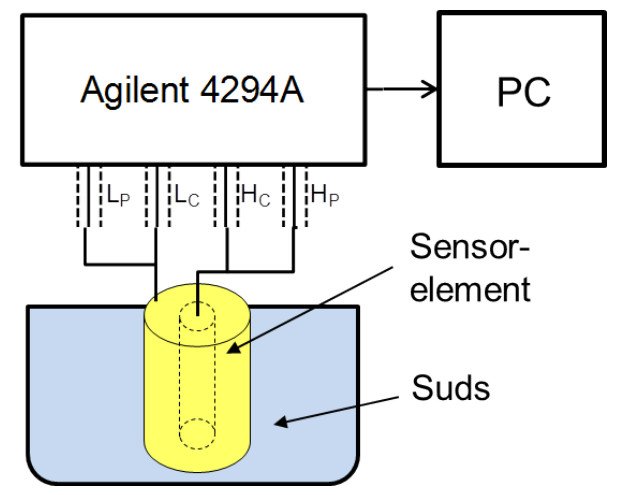

Figure 2. Measurement setup of Agilent 9294A for EIS measurements (Gruden and Kanoun, 2013b).

The combination of these measuring principles provides more data from different frequency ranges and allows more detailed investigations. The focus of this fluid analysis is the analysis of data and not to electrochemical effects of the sensor element. With this method, expensive sensors and environmentally harmful materials can be avoided. Due to the fact that frequencies of $f_{\max }=5 \mathrm{MHz}$ are needed, the cost of the electronic circuit is adequate for the planned application.

The focus of this paper is the investigation of predefined water samples and one standard detergent, and to ignore real water samples and commercial detergents because the feasibility of this new method should be tested. Tests with real water samples and commercial detergents can be investigated later.

\section{Experimental}

The experimental setup for electrochemical impedance spectroscopy (EIS) and cyclic voltammetry (CV) consisted of a Zahner Zennium impedance analyzer for frequency range $0.1 \mathrm{~Hz}$ to $4 \mathrm{MHz}$ and an Agilent 9294A impedance analyzer (used for EIS only) with measurement adapter Agilent 
Table 1. List of water samples with a total hardness of $1.48 \mathrm{mmol} \mathrm{L}^{-1}\left(1.48 \mathrm{mmol} \mathrm{L}^{-1}\right)$ and different carbonat hardness caused by different $\mathrm{HCO}_{3}^{-} / \mathrm{Cl}^{-}$ratio.

\begin{tabular}{llll}
\hline $\begin{array}{l}\text { Carbonate- } \\
\text { hardness }\left(\mathrm{mmol} \mathrm{L}^{-1}\right)\end{array}$ & $\begin{array}{l}\mathrm{HCO}_{3}^{-} / \mathrm{Cl}^{-} \\
\text {ratio }\end{array}$ & $\begin{array}{l}\text { Conductivity } \chi \mathrm{E} \\
\left(\mu \mathrm{S} \mathrm{cm}^{-1}\right)\end{array}$ \\
\hline 1 & 0 & $\mathrm{Cl}^{-}$only & 411.5 \\
2 & 0.25 & $1: 1.35$ & 392.7 \\
3 & 0.5 & $1: 0.63$ & 374.3 \\
4 & 0.69 & $1: 0.25$ & 347.4 \\
5 & 0.93 & $\mathrm{HCO}_{3}^{-}$only & 337.8 \\
\hline
\end{tabular}

$16048 \mathrm{H}$ for frequency range of $40 \mathrm{~Hz}$ to $110 \mathrm{MHz}$. All tests were carried out with a homemade cylindrical sensor element with gold electrodes and two-electrode configuration. Figure 1 shows the setup for the Zahner Zennium and Fig. 2 shows the setup for the Agilent 9294A.

For future application a low-cost electronic is planned and a prototype exists. The sensor element is made of ceramic with a $500 \mathrm{~nm}$ gold surface.

The temperature control was a Julabo LH46 Presto and a double-walled integral exchanger reactor. High purity water prepared with a Siemens LaboStar UV7 immediately before the experimental procedure was the basis of all applied solutions. The synthetic water samples were manufactured according to IEC 60734:2003 (IEC60734, 2003) and the custom-made Seuffer procedure.

The reference measurement of each water sample was carried out with the titrator TA20plus and the software TitriSoft 2.6 from SI-Analytics. Reference detergent IEC A/IEC 60456 (wfk, IEC60456 ${ }^{2}$ ) of wfk-Testgewebe $\mathrm{GmbH}$ were used for the suds. The water samples for the experiments with different values of carbonate hardness (see Table 1) are equal except for the hydrogen carbonate/chloride ratio $\left(c\left(\mathrm{HCO}_{3}^{-}+\mathrm{Cl}^{-}\right)=2.56 \mathrm{mmol} \mathrm{L}^{-1}=\right.$ const. $)$. All these samples have a total ion concentration of $c_{\text {ion }}=4.2 \mathrm{mmol} \mathrm{L}^{-1}$ (Gruden and Kanoun, 2013a).

\section{Results and discussion}

The approach is to combine impedance spectroscopy and cyclic voltammetry in order to have a detailed water analysis as a basis for optimal detergent dosage. By means of impedance spectroscopy, the exact conductivity of the medium can be determined and changes in the composition of the medium can be detected. At the same time, the relative concentration $\alpha_{\text {ion }}$ (see Eqs. 1 and 2) of the species can be quantified by cyclic voltammetry. Many measurements have been carried out and show the feasibility of the combined measurement principle.

\footnotetext{
${ }^{2}$ wfk: IEC A* Referenzwaschmittel nach IEC 60456 Order Code: 88010-1, WFK IEC A*, wfk-Testgewebe GmbH, BrüggenBracht.
}

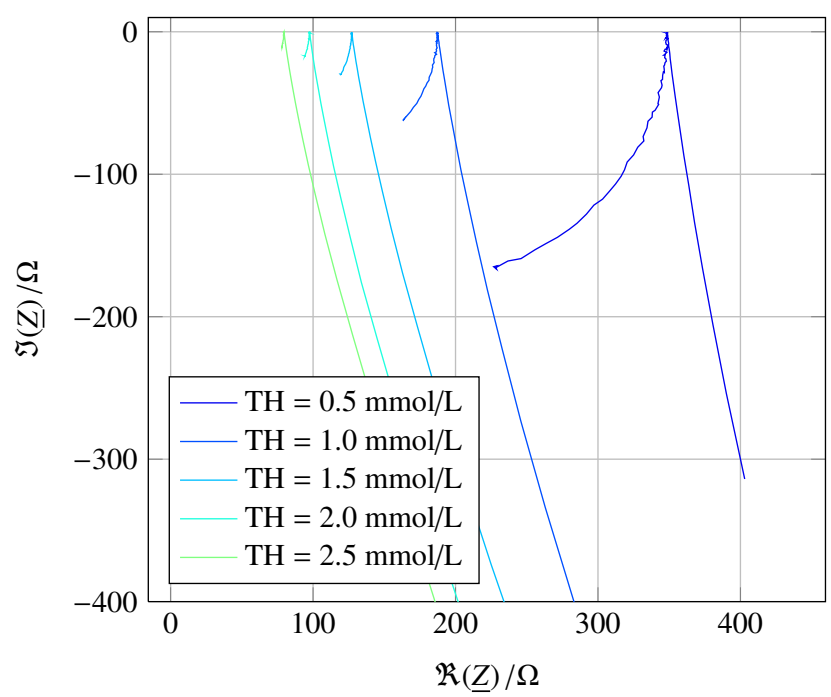

Figure 3. Dependence of the impedance spectra on total hardness of water.

Table 2. MTP frequencies of the impedance spectras of Fig. 3.

\begin{tabular}{rr}
\hline $\mathrm{TH}\left[\mathrm{mmol} \mathrm{L}^{-1}\right]$ & Frequency $f[\mathrm{kHz}]$ \\
\hline 0.5 & 3.5 \\
1.0 & 7.0 \\
1.5 & 17.8 \\
2.0 & 20.0 \\
2.5 & 35.5 \\
\hline
\end{tabular}

$$
\begin{aligned}
& c_{\text {ion }}=c_{\mathrm{Ca}^{2+}}+c_{\mathrm{Mg}^{2+}}+c_{\mathrm{Na}^{+}}+c_{\mathrm{HCO}_{3}^{-}}+c_{\mathrm{Cl}^{-}}+c_{\mathrm{SO}_{4}^{2-}} \\
& 1=\alpha_{\mathrm{Ca}^{2+}}+\alpha_{\mathrm{Mg}^{2+}}+\alpha_{\mathrm{Na}^{+}}+\alpha_{\mathrm{HCO}_{3}^{-}}+\alpha_{\mathrm{Cl}^{-}}+\alpha_{\mathrm{SO}_{4}^{2-}}
\end{aligned}
$$

Figure 3 shows the impedance spectra of water samples with different values of total hardness of water.

The impedance spectra are qualitatively equal because of the identical composition of the water samples. The maximum turning point (see Fig. 4) of the impedance spectra is equal to the resistance of the electrolyte $R_{\mathrm{E}}$ and is frequency dependent.

The frequency values of the MTP of the spectras of Fig. 3 are shown in Table 2.

The advantage of impedance spectroscopy compared to the usual single frequency conductance measurement is that the maximum turning point, and thus $R_{\mathrm{E}}$, can be precisely determined by the multi-frequency method. The conductance $G_{\mathrm{E}}$ (reciprocal of $R_{\mathrm{E}}$ ) correlates linearly with the total hardness of water (see Fig. 5) with a correlation coefficient of $r=0.9997$.

Therefore, the resulting sensitivity of $S_{\mathrm{TH}}=$ $4.85 \mathrm{mS} \mathrm{L} \mathrm{mmol}^{-1}$ is very good for the planned application. 


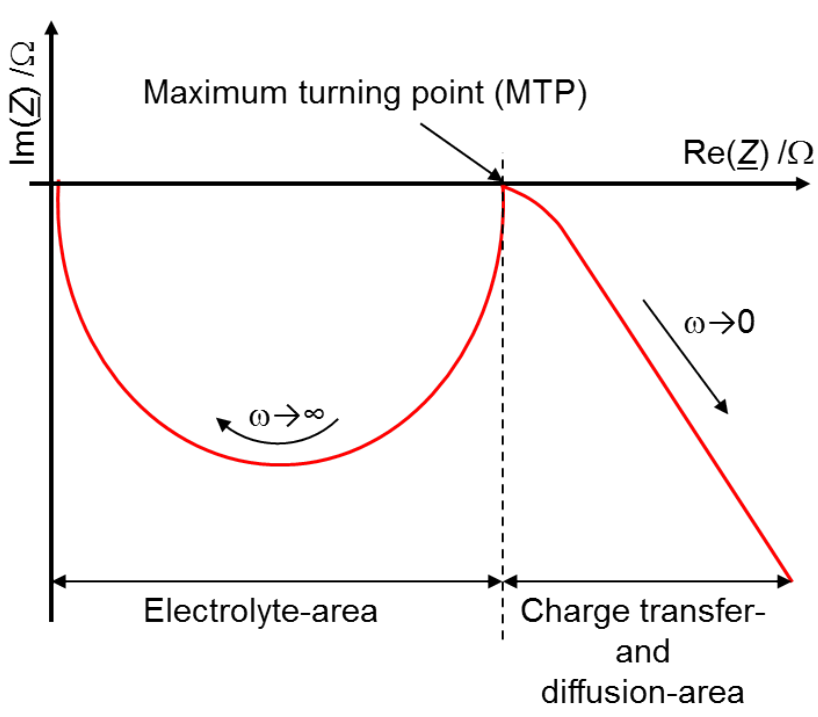

Figure 4. Qualitative plot of an impedance spectra.

This high correlation is only achievable with synthetic water by use of the precise impedance spectroscopy method. A statistic of 124 real water samples of different German areas shows that the correlation coefficient of these water samples is $r=0.8568$. The difference between synthetic and real water is caused by the different ion concentrations of the ions which do not contribute to total hardness (see Table 3, Eqs. 3 and 4).

$$
\begin{aligned}
\chi_{\mathrm{E}}^{0} & =c_{\mathrm{Ca}^{2+}} \cdot \Lambda_{\mathrm{Ca}^{2+}}^{0}+c_{\mathrm{Mg}^{2+}} \cdot \Lambda_{\mathrm{Mg}^{2+}}^{0}+c_{\mathrm{Na}^{+}} \cdot \Lambda_{\mathrm{Na}^{+}}^{0} \\
& +c_{\mathrm{HCO}_{3}^{-}} \cdot \Lambda_{\mathrm{HCO}_{3}^{-}}^{0}+c_{\mathrm{Cl}^{-}} \cdot \Lambda_{\mathrm{Cl}^{-}}^{0}+c_{\mathrm{SO}_{4}^{2-}} \cdot \Lambda_{\mathrm{SO}_{4}^{2-}}^{0} \\
\overline{\chi_{\mathrm{TH}}} & =\overline{\chi_{\mathrm{E}}}-\chi_{\varepsilon} \rightarrow \overline{\chi_{\mathrm{TH}}} \approx \overline{\chi_{\mathrm{E}}}
\end{aligned}
$$

The relationship between conductance $G_{\mathrm{E}}$ and conductivity $\chi_{\mathrm{E}}$ is given by the cell constant $K$ of the sensor element.

$\chi_{\mathrm{E}}=G_{\mathrm{E}} \cdot K$

The conductivity, $\chi_{\mathrm{E}}$, of the water sample is composed of the concentration of each species, $c_{\mathrm{SP}}$, multiplied by its molar limit conductivity, $\Lambda^{0}$. The portion of conductivity which represents the total hardness of water, $\chi_{\mathrm{TH}}$, cannot be clearly defined because of the different combination possibilities of the hardness forming cations $\mathrm{Ca}^{2+}$ and $\mathrm{Mg}^{2+}$ with its possible corresponding anions $\mathrm{HCO}_{3}^{-}, \mathrm{Cl}^{-}$and $\mathrm{SO}_{4}^{2-}$. All combinations between the cations and anions are possible and lead to different conductivities which do not correlate to the chemical effects. The arithmetic mean of $\chi_{\mathrm{TH}}$ equals $\chi_{\mathrm{E}}$ if the fault $\chi_{\varepsilon}$ is low or the requirements to the results are not strict. This results in the need for a differentiated analysis of ions in case of precise measurement requirements.

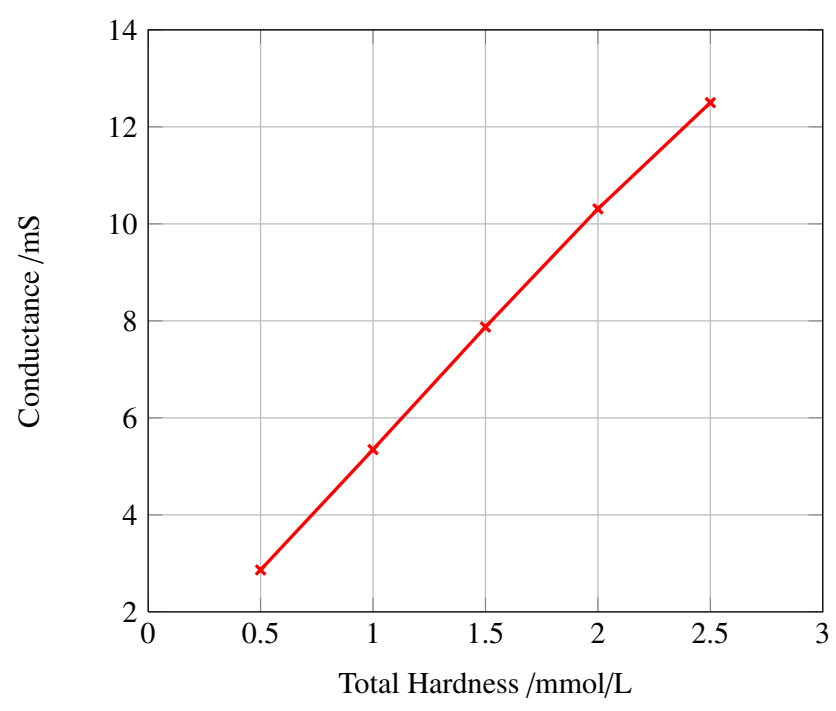

Figure 5. Dependence of the conductance on total hardness of water.

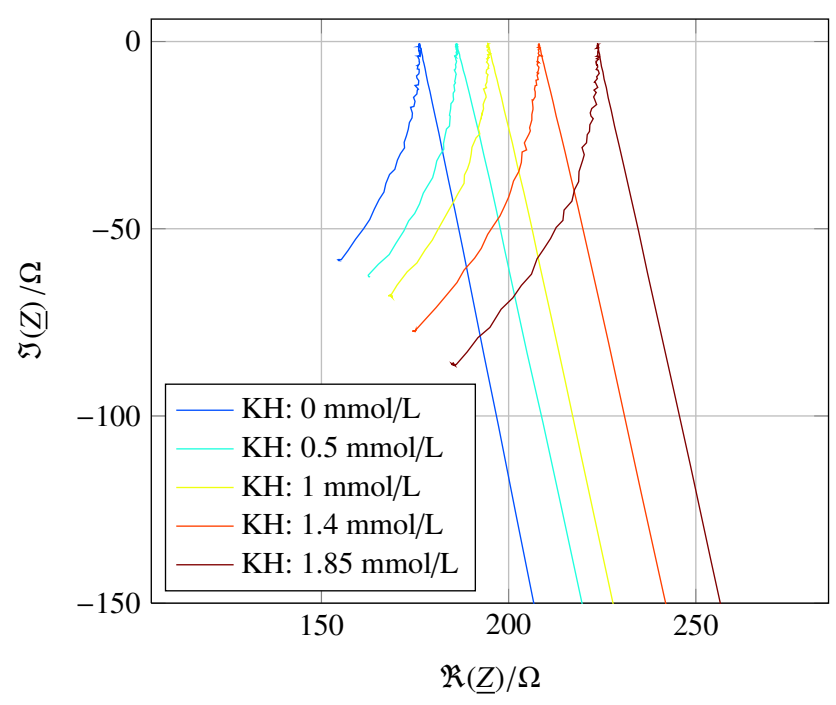

Figure 6. Impedance spectra of water samples with the same total hardness and different carbonate hardness.

Figure 6 shows the impedance spectra of five water samples, all of them has a total hardness of $1.48 \mathrm{mmol} \mathrm{L}^{-1}$ $\left(8.31^{\circ} \mathrm{dH}\right)$ but different carbonate hardness values (see Table 1).

All spectra are qualitatively equal. The frequency of the MTP is $f=7 \mathrm{kHz}$ at all spectras and the highest frequency point is $f=4 \mathrm{MHz}$. To distinguish them from the spectra of different total hardness values, further information by an additional measurement principle is necessary.

Figure 7 shows a schematic diagram of two cyclic voltammetry measurements.

At $t_{\mathrm{I}}$ the different current responses $\left(I_{1}\right.$ and $\left.I_{2}\right)$ are used to distinguish carbonate hardness. At $I_{\mathrm{t}}$ the different relaxation 
Table 3. List of the ions which contribute mainly to the total ion concentration of water.

\begin{tabular}{lll}
\hline Ion & Contribution to & Remarks \\
\hline $\mathrm{Ca}^{2+}$ & Total hardness (TH) & $\begin{array}{l}\text { Together with } \mathrm{Mg}^{2+} \text { main ion for TH } \\
\text { Together with } \mathrm{Ca}^{2+} \text { main ion for TH }\end{array}$ \\
$\mathrm{Mg}^{2+}$ & Total hardness (TH) & - \\
\hline $\mathrm{Na}^{+}$ & Only total ion concentration (TIC) & - \\
$\mathrm{K}^{+}$ & Only total ion concentration (TIC) & - \\
\hline $\mathrm{HCO}_{3}^{-}$ & Carbonate hardness (KH) & \\
$\mathrm{Cl}^{-}$ & Non carbonate hardness (NKH) & All anions contribute to the conductivity of the total hardness, depending on the composition. \\
$\mathrm{Cl}^{-}$ & Non carbonate hardness (NKH) & All anions contribute to the conductivity of the total hardness, depending on the composition. \\
$\mathrm{SO}_{4}^{2-}$ & Non carbonate hardness (NKH) & \\
\hline
\end{tabular}

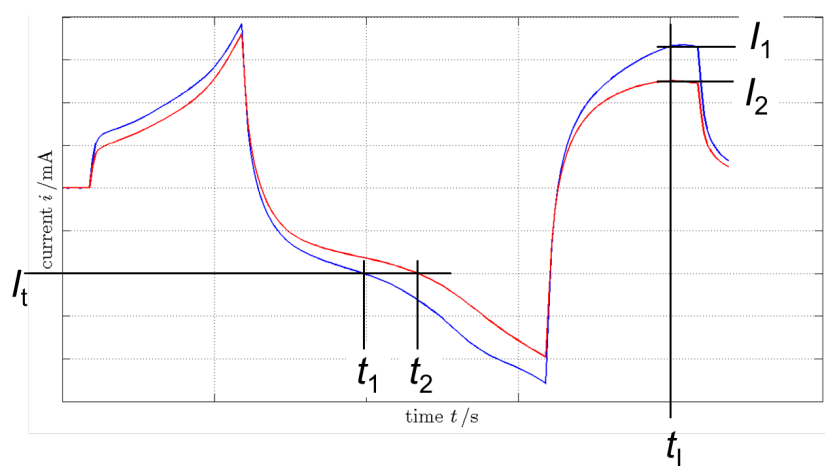

Figure 7. Two typical cyclic voltammetry measurements of different water samples.

times $\left(t_{1}\right.$ and $\left.t_{2}\right)$ are used to distinguish calcium-magnesiumratios.

Figure 8 shows the results of the water investigation by cyclic voltammetry.

A sensitivity of $S_{\mathrm{i}}=-6.7 \mu \mathrm{A} \mathrm{L} \mathrm{mmol}{ }^{-1}$ was reached, which is sufficient for the target application. The absolute value of current $I$ decreases linearly with the increasing carbonate hardness; the reason is that the ratio of the anions changes. The concentration of $\mathrm{HCO}_{3}^{-}$increases and the concentration of $\mathrm{Cl}^{-}$ions decrease. $\mathrm{Cl}^{-}$ions have a higher contribution to the conductivity than $\mathrm{HCO}_{3}^{-}$.

Figure 9 shows the impedance spectra of water samples with identical total and carbonate hardness but with a different calcium-magnesium-ratio.

The frequency of the MTP is $f=4 \mathrm{kHz}$ at all spectras and the maximum frequency is $f=4 \mathrm{MHz}$. The impedance spectra are qualitatively and quantitatively identical and thus it is not possible to distinguish different calcium-magnesiumratios by impedance spectroscopy. The water samples are nearly identical from electrochemical point of view because the earth alkaline metals calcium and magnesium behave very similar.

Figure 10 shows the result of an investigation of the water samples by cyclic voltammetry.

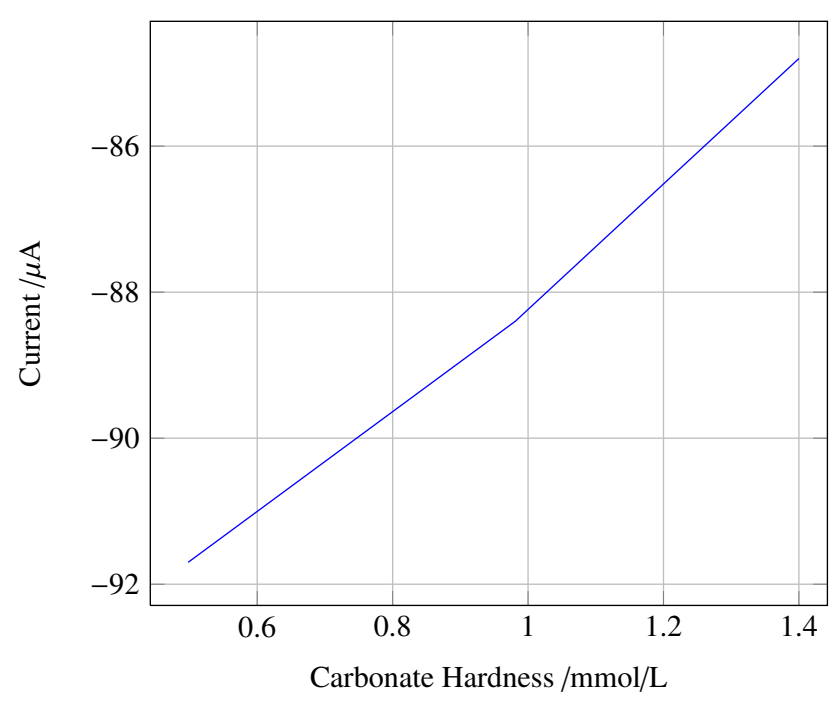

Figure 8. Current response as a function of carbonate hardness.

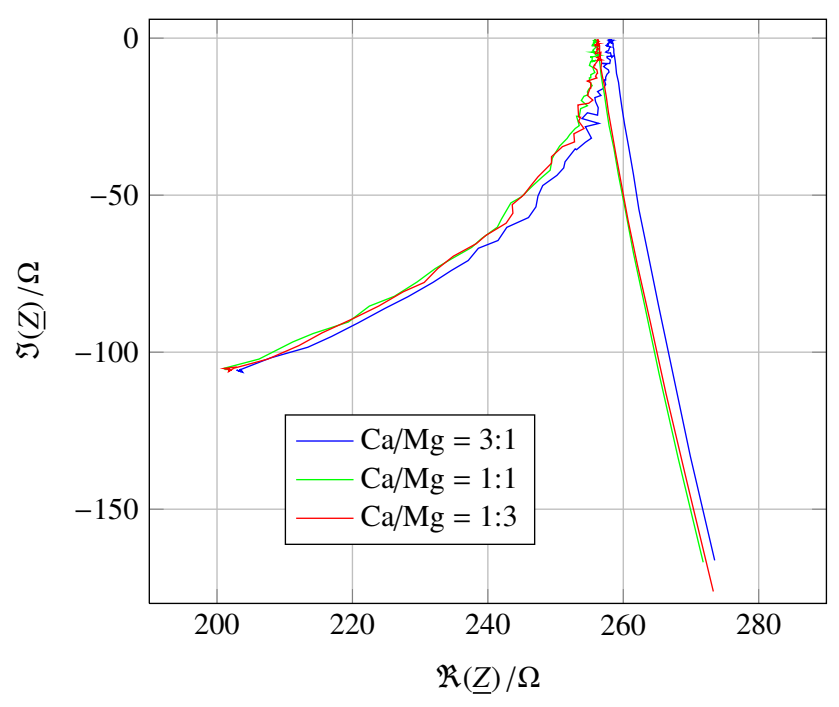

Figure 9. Impedance spectra of water samples with the same total and carbonate hardness but different $\mathrm{Ca} / \mathrm{Mg}$ ratio $\left(\mathrm{mmol} \mathrm{L}^{-1}\right)$. 


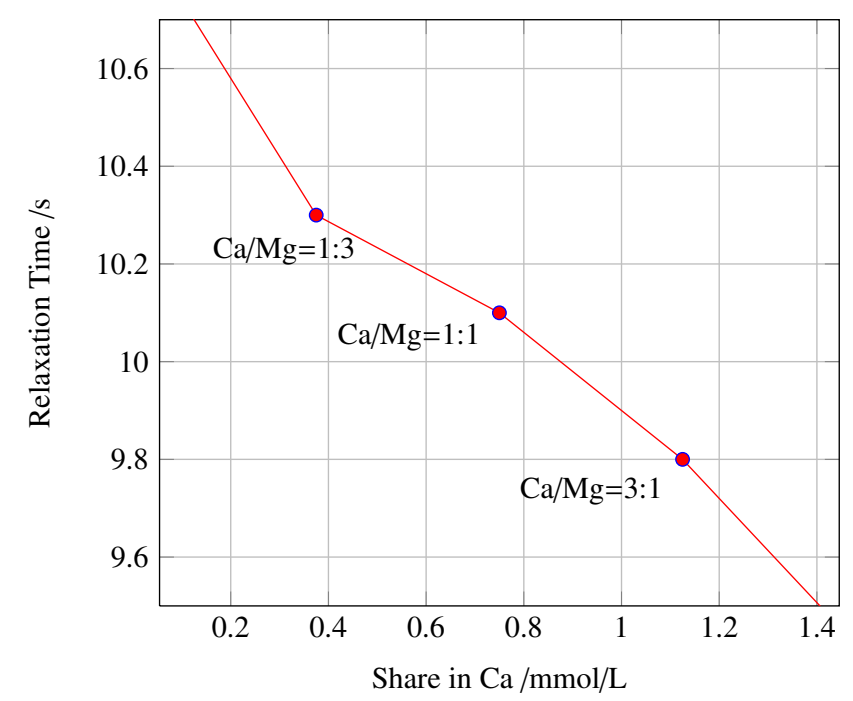

Figure 10. Relaxation time depending on calcium-magnesiumratio.

A correlation of the relaxation time and the $\mathrm{Ca} / \mathrm{Mg}$ ratio can be clearly seen. The relaxation time depends on the ionic radii of the species. Different radii mean different speeds of the ions. The resolution of the sensor signal to distinguish the different calcium-magnesium-ratios is an important factor for the planned application. For this experiment, solutions with different calcium-magnesium-ratios were used, the total concentration was constant.

$c_{\text {tot }}=c(\mathrm{Ca})+c(\mathrm{Mg})=1.5 \mathrm{mmolL}^{-1}=$ const.

Figure 11 shows the results of the relative current responses of different calcium-magnesium-ratios. The curves are scaled that if the $\mathrm{Ca} / \mathrm{Mg}$ ratio is $1: 1(c(\mathrm{Mg})=c(\mathrm{Cl}))$ the current response is zero $(I=0)$. Differences from a balanced $\mathrm{Ca} / \mathrm{Mg}$ ratio can be easily seen. Deviations lead to a current response $I \neq 0$ and the sensitivity of the sensor is $S \approx$ $0.9 \mathrm{~s} \mathrm{~L} \mathrm{mmol}^{-1}$ of $\mathrm{Ca}$ which is adequate for the planned application.

The results of $\mathrm{Ca} / \mathrm{Mg}$ ratio measurement could be confirmed only with synthetic water samples. Tests with real water samples could not confirm the laboratory results within the needed precision. The reasons for these different results could be the cross-sensitivity of the sensor system to other ions. A new approach to enlarge the measurement method by further tests to suspend the influence of other ions is in progress.

These three characteristics of water (total hardness of water, carbonate hardness and calcium-magnesium-ratio) are important for detergent dosage and have direct influence on the washing result (personal communication, 2012). The washing performance depends on the carbonate hardness and the $\mathrm{Ca} / \mathrm{Mg}$ ratio because hydrogen carbonate ions react to insoluble calcium carbonate and attach to the laundry and on the heating elements of the washing machine, and calcium

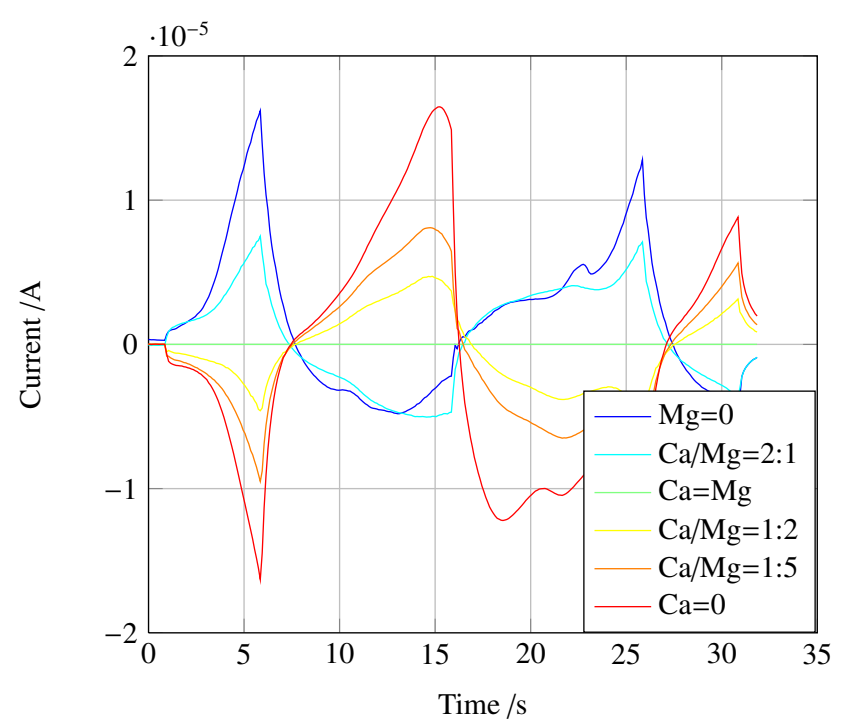

Figure 11. Relative current response of different $\mathrm{Ca} / \mathrm{Mg}$-ratios based on a balanced $\mathrm{Ca} / \mathrm{Mg}$-ratio.

and magnesium form salts with different solubility. All other ions, which also have impact on the washing process are not represented in this investigation. These ions will investigated later.

The new unit AQrate will be introduced to characterize water.

$$
\begin{aligned}
& \text { AQrate }=f(\mathrm{TH}, \mathrm{KH}, \mathrm{Ca} / \mathrm{Mg}) \\
& \mathrm{TH}=c\left(\mathrm{Ca}^{2+}+\mathrm{Mg}^{2+}\right) \\
& \mathrm{KH}=c\left(\mathrm{HCO}_{3}^{-}\right) \\
& \mathrm{Ca} / \mathrm{Mg}=\frac{c\left(\mathrm{Ca}^{2+}\right)}{c\left(\mathrm{Mg}^{2+}\right)}
\end{aligned}
$$

For detergent dosage recommendation AQrate will replace total hardness of water in a first step because it is much more precise and meaningful.

Figure 12 shows the impedance spectra of suds with different concentrations $c_{\text {det }}$ and Table 4 shows the frequencies of the MTP.

The maximum turning points (MTP) correlate strongly with the concentration of the suds $(r \approx 1)$ as long as they do not exceed a certain value (see Fig. 13).

Above this concentration $c_{\mathrm{CMC}}$, the conductivity increases again linearly with the concentration, but with a lesser gradient. Thus there are two lines and their intersection point marks the critical micelle concentration (CMC) (Nakamura et al., 1998; Neto et al., 2006; Chang et al., 1998). There is a strong presumption that the optimum detergent concentration is close to the critical micelle concentration. On this issue intensive tests are currently being carried out (Gruden and Kanoun, 2013a). 


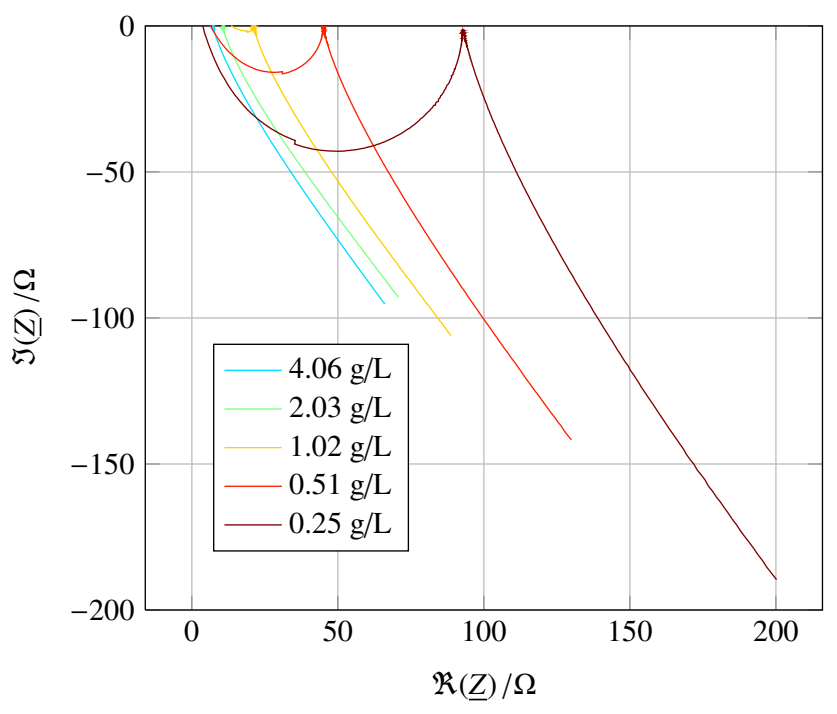

Figure 12. Dependence of the IS on detergent concentration.

Table 4. MTP frequencies of the impedance spectras of Fig.12.

\begin{tabular}{rr}
\hline$c\left[\mathrm{~g} \mathrm{~L}^{-1}\right]$ & Frequency $f[\mathrm{kHz}]$ \\
\hline 0.25 & 48.4 \\
0.51 & 71.4 \\
1.02 & 153 \\
2.03 & 172 \\
4.06 & 191 \\
\hline
\end{tabular}

\section{Conclusion and outlook}

The results indicate that it is possible to determine the detergent concentration of suds and the parameters of water which have impact on the washing process by a combination of impedance spectroscopy (EIS) and cyclic voltammetry (CV). The results of $\mathrm{Ca} / \mathrm{Mg}$ ratio measurement could be confirmed only with synthetic water samples. Tests with real water samples could not confirm the laboratory results of $\mathrm{Ca} / \mathrm{Mg}$ ratio within the needed precision. A big advantage of impedance spectroscopy as a multi-frequency method in comparison to conventional conductance measuring methods is the possibility to determine $R_{\mathrm{E}}$ precisely and thus form a solid basis for all further investigations. Moreover, further investigations are in progress to get more information from the impedance spectra to improve the planned application.

The detergent concentration of the suds can be measured precisely by impedance spectroscopy as well. The implementation of this method for the CMC detection and thus the optimization of the detergent amount and the washing process is in progress.

To determine the carbonate hardness and the calciummagnesium-ratio, a combination of the results of impedance spectroscopy and cyclic voltammetry is necessary and the results show the feasibility.

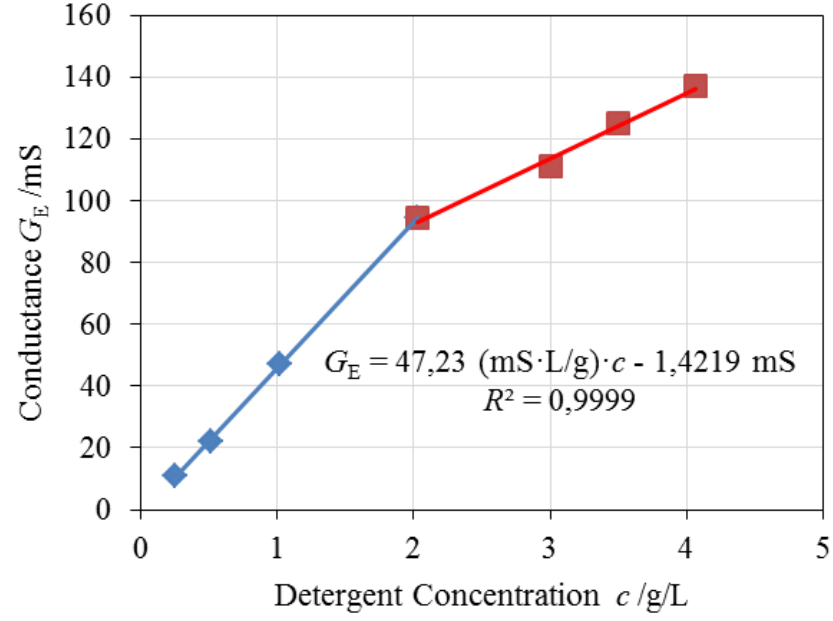

Figure 13. Dependence of the conductance on detergent concentration.

Both methods can be realized with the same sensor element and the same hardware. The planned application can be realized as a low cost solution for an online measurement during the washing process without environmentally harmful substances. The realized measurements indicate the feasibility of the planned application. For a final version some points like the online detection of the critical micelle concentration and the precise correlation of the measurement data to the water parameters still has to be clarified. Such tests are in progress.

The new unit AQrate has to be specified and will be extended by additional ion effects. With such adaptations, the new unit AQrate can consider region-specific characteristics of water.

Edited by: A. L. Spetz

Reviewed by: two anonymous referees

\section{References}

Barsoukov, E. and Macdonald, J. R.: Impedance Spectroscopy, Wiley-Interscience, 2005.

Brad, A. J. and Faulkner, L. R.: Electrochemical Methods, John Wiley \& Sons, 2001.

Cammann, K. and Galster, H.: Das Arbeiten mit ionenselektiven Elektroden, Springer Verlag, 1996.

Chang, H.-C., Hwang, B.-J., Lin, Y.-Y., Chen, L.-J., and Lin, S.-Y.: Measurement of critical micelle concentration of nonionic surfactant solutions using impedance spectroscopy technique, Rev. Sci. Instrum., 69, 2514-2520, 1998.

Czyzewski, G., Schulze, I., and Engel, C.: Europäische Patentanmeldung EP 0992622 A2, 1999.

Eriksson, M., Lindgren, D., Bjorklund, R., Winquist, F., Sundgren, H., and Lundström, I.: Drinking Water monitoring with voltammetric sensors, Procedia Engineering, 25, 1165-1168, 2011.

Gruden, R., Kanoun, O., and Tröltzsch, U.: Influence of surface effects on the characterisic curves of detergent sensors, 9th In- 
ternational Multi-Conference on Signals, Sensors and Devices, Chemnitz: 20-23 März 2012.

Gruden, R. and Kanoun, O.: Water quality assessment by combining impedance spectroscopy measurement with cyclic voltammetry, AMA Sensor, Nürnberg, 2013a.

Gruden, R. and Kanoun, O.: Fast and Low-Cost Online Detection of Critical Micelle Concentration based on Impedance Specroscopy, The 7th International Conference on Sensing Technology, 3-5 December, Wellington, New Zealand, 2013b.

Huang, Z., Li, K., and Xu, H.: Research of an online measurement and control system of water-quality on FIA, Chinese Journal of Scientific Instrument 36, 343-346 + 385, 2005.

Hütter, L. A.: Wasser und Wasseruntersuchung, Otto Salle Verlag und Verlag Sauerländer, 1990.

IEC60734: Household electrical applicances Performance - Hard water for testing (IEC 60734:2003), CENELEC (European Committee for Electrotechnical Standardization), Brussels, 2003.

Ivarsson, P.: Electronic Tongues - New Sensor Technology in Household Appliances, Linköping, Sweden, 2003.

Jakobi, G. and Löhr, A.: Detergents and Textile Washing, VCH, 1987.

Kräuter, S., Lange, R., and Seifert, F.: Surface water quality measuring station adaptable to changing requirements, Water and Wastewater International, 21, p. 41, 2006.

Nakamura, H., Sano, A., and Matsuura, K.: Determination of Critical Micelle Concentration of Anionic Surfactants by Capillary Electrophoresis Using 2-Naphthalenemethanol as a Marker for Micelle Formation, Journal of Analytical Sciences, 14, 379-382, 1998.

Neto, J. M. G., da Cunha, H. N., Neto, J. M. M., and Ferreira, G. F. L.: Impedance spectroscopy analysis in a complex system: Sodium dodecyl sulfate solutions, J. Sol-Gel Sci. Techn., 38, 191-195, 2006.
Pungor, E., Nagy, G., and Feher, Z.: The flat surfaced membrane coated mercury electrode as analytical tool in the continuous voltammetric analysis, J. Electroanal. Chem., 75, 241-254, 1977.

Rüdenauer, I. and Gensch, C.-O.: Einsparpotentiale durch automatische Dosierung bei Waschmaschinen, Öko-Institut e.V., Studie im Auftrag der Miele \& Cie. KG, 2008.

Smulders, E., Rähse, W., von Rybinski, W., Steber, J., Sung, E., and Wiebel, F.: Laundry Detergents, Wil, 2002.

Tröltzsch, U.: Anwendungspotential der Impedanzspektroskopie für die Waschlaugensensorik, 16. GMA/ITG-Fachtagung Sensoren und Messsysteme, 650-661, 2012.

Tschulena, G. and Lahrmann, A.: Sensors in Household Appliances, Wiley-VCH, 2006.

Verberk, J. Q. J. C., Hamilton, L. A., O’Halloran, K. J., Van Der Horst, W., and Vreeburg, J.: Analysis of particle numbers, size and composition in drinking water transportation pipelines: Results of online measurements, Wa. Sci. Technol., 6, 35-43, 2006.

Vivancos, J.-L., Rácz, Z., Cole, M., and Gardner, J. W.: Surface acoustic wave based analytical system for the detection of liquid detergents, Sensor. Actuat. B-Chem., 171, 469-477, 2012.

Wagner, G.: Waschmittel, Viley VCH, 2010.

Winquist, F.: Voltammetric electronic tongues - basic principles and applications, Microchim. Acta, 163, 3-10, 2008.

Winquist, F., Wide, P., and Lundström, I.: An electronic tongue based on voltammetry, Anal. Chim. Acta, 357, 21-31, 1997.

Winquist, F.: Multicomponent analysis of drinking water by a voltammetric electronic tongue, Anal. Chim. Acta, 683, 192197, 2011. 